\title{
Invasive alien plants affect grassland ant communities, colony size and foraging behaviour
}

\author{
Magdalena Lenda $\cdot$ Magdalena Witek • Piotr Skórka • \\ Dawid Moroń $\cdot$ Michał Woyciechowski
}

Received: 16 September 2012/Accepted: 10 April 2013/Published online: 27 April 2013

(C) The Author(s) 2013. This article is published with open access at Springerlink.com

\begin{abstract}
Ants are dominant members of many terrestrial ecosystems and are regarded as indicators of environmental changes. However, little is known about the effects of invasive alien plants on ant populations, particularly as regards the density, spatial distribution and size of ant colonies, as well as their foraging behaviour. We addressed these questions in a study of grassland ant communities on five grasslands invaded by alien goldenrods (Solidago sp.) and on five non-invaded grasslands without this plant. In each grassland, seven $100 \mathrm{~m}^{2}$ plots were selected and the ant colonies counted. Ant species richness and colony density was lower in the plots on the invaded grasslands. Moreover, both of these traits were higher in the plots near the grassland edge and with a higher number of plant species in the grasslands invaded by goldenrods but not in the non-invaded ones. On average, ant colony size was lower on the invaded
\end{abstract}

Electronic supplementary material The online version of this article (doi:10.1007/s10530-013-0461-8) contains supplementary material, which is available to authorized users.

M. Lenda $(\bowtie)$

Institute of Nature Conservation, Polish Academy of Sciences, Mickiewicza 33, 31-120 Kraków, Poland

e-mail: lenda@iop.krakow.pl

M. Witek

Museum and Institute of Zoology, Polish Academy of

Sciences, Wilcza 64, 00-679 Warsaw, Poland

P. Skórka

Institute of Zoology, Poznan University of Life Sciences,

Wojska Polskiego 71C, 60-625 Poznan, Poland grasslands than the non-invaded ones. Also, ant workers travelled for longer distances to collect food items in the invaded areas than they did in the non-invaded ones, even after the experimental removal of some ant colonies in order to exclude the effect of higher colony density in the latter. Our results indicate that invasive alien goldenrods have a profound negative effect on grassland ant communities which may lead to a cascade effect on the whole grassland ecosystem through modification of the interactions among species. The invasion diminishes a major index of the fitness of ants, which is a colony's size, and probably leads to increased foraging effort of workers. This, in turn, may have important consequences for the division of labour and reproductive strategies within ant colonies.

Keywords Biodiversity · Edge effect · Indicators · Invasive alien species $\cdot$ Plant species richness

D. Moroń

Institute of Systematics and Evolution of Animals, Polish Academy of Sciences, Sławkowska 17, 31-016 Kraków, Poland

M. Woyciechowski

Institute of Environmental Sciences, Jagiellonian University, Gronostajowa 7, 30-387 Kraków, Poland 


\section{Introduction}

Ants are one of the most widely distributed and abundant group of insects and they usually have high species diversity and biomass, as well as numerical dominance in various habitats and they interact with many organisms at every trophic level (Fittkau and Klinge 1973; Agosti et al. 1994, 2000). Ants have recently received a great deal of attention as a possible use as an indication group due to their sensitivity to changes in the environment (Agosti et al. 2000; Andersen et al. 2002; Andersen and Majer 2004). One of the most significant drivers of the environmental change worldwide is invasive alien species (Zanden and Casselman 1999; Lach 2007; Clout and Williams 2009). Alien plants may change nutrient cycles, affect interactions between native species and are often superior competitors for limited resources in comparison with their native counterparts (Traveset and Richardson 2006; Funk and Vitousek 2007). Invasive alien species are so troublesome that their colonization and population growth often give rise to substantial economic loss in agriculture, aquaculture or nature conservation (Clout and Williams 2009; Pejchar and Mooney 2009; Lenda et al. 2010). It has also been documented that certain invasive alien species may add to species extinction (Clavero and García-Berthou 2005).

It has been shown that local populations of pollinators, such as bees, hoverflies or butterflies and some ground-living beetles, may be negatively affected by invasions of alien plants (de Groot et al. 2007; Moroń et al. 2009). Invasive alien plants both out-compete native plants, which are major food resources for these animals, and/or change environmental features in habitats, making them unsuitable for certain species (Funk and Vitousek 2007). Native plant species are also an important component of the habitats of ants, and the structural heterogeneity of plant communities has been shown to be positively related to ant species richness (Rico-Gray et al. 1998; Ribas and Schoereder 2007; Schlick-Steiner et al. 2008). Thus, one may expect a positive dependence of ant species richness on the number of plant species. On the other hand, most ant species are opportunistic predators or scavengers and do not depend directly on native plant populations and they may change food resources when they occur in invaded areas.

Many ant species are also vey sensitive to even little changes in their habitats (Dauber and Wolters 2004;
Agosti et al. 2000), thus one may predict that deep changes caused by invasive plant species should negatively affect ant species richness and density of colonies and ant foraging behaviour. The effect of invasive alien plant species on ants may vary spatially, though. For example, the areas in the centre of the habitat patch usually differ from those at the habitat patch edges (Gehlhausen et al. 2000; Euskirchen et al. 2001; Lindenmayer and Fischer 2006). This may lead to the emergence of an edge effect, with ant species richness and density of colonies different between centre and edge of the habitat patch (Dauber and Wolters 2004). To date, however, there is little knowledge about how invasive alien plants affect ant community structure and indigenous ant colony size (French and Major 2001; Alba-Lynn and Henk 2010), and whether the structural heterogenity index (plant species richness) and proximity of edges in the habitat patch affect ant communities in the same way in the invaded and non-invaded habitats. Such data are thus required in order to understand if ants are resistant to plant invasion and how they respond to this environmental change. This, in turn, may prove to be useful information in the prediction of an entire ecosystem's response to invasion.

In this study, we analyzed the effects of invasive alien goldenrods (Solidago sp.), which are the most widespread alien species in Europe (Weber 2001), on native grassland ant communities. Goldenrods in invaded areas usually grow in dense monospecific stands (Dong et al. 2006; de Groot et al. 2007) and it has been shown that local populations of pollinators, such as bees, hoverflies or butterflies, some groundliving beetles and birds may be negatively affected by invasions of goldenrods (de Groot et al. 2007; Moroń et al. 2009; Skórka et al. 2010). Thus we expected that the number of ant species and the density of colonies will be lower in invaded areas. However, the effects of invasive alien goldenrods on ants' populations may be more subtle than changes only in the proportion of species or density of colonies and it is also possible that ant colony sizes may be affected first. Colony size is a very important characteristic, because greater colony size is associated with a better competitive ability and increased probability of finding food (Herbers and Choiniere 1996; Walin et al. 2001; Palmer 2004). Moreover, it is unclear as to how invasive alien plants may affect colony size. When resources for ants are diminished, which is to say, a 
low number of seeds and arthropods, then the colony size should be lower, because the restricted resources are enough for only a limited number of colony members. However, one may expect that low resources might be replenished by higher foraging effort or making more risky, longer trips to find food (Gordon 1995; Moroń et al. 2008a, b, 2012). Moreover, if the invasive alien plant negatively affects the density of ant colonies, the size of the colony may remain unchanged, or even increase, because the lower supply of resources may be balanced by simultaneous lower inter-colony competition (Petal 1982). These questions are important to the understanding of the mechanism of the invasive alien plants' impact on ants, both at the community and colony level. Thus, the aim of this paper is to analyze how the invasion of alien goldenrods in grassland landscapes affects the number of ant species, the density and spatial distribution of their colonies, as well as the colony size and foraging distances.

\section{Methods}

The study was carried in out in July and August 2006 and 2007 in agricultural landscapes located in Southern Poland, in the north-western areas of the cities of Kraków and Tarnów. The dominant landscape type in these areas is arable land. Cereal crops, primarily wheat, cover $35 \%$ of the study area; root crops, mainly potatoes and beets, cover $15 \%$; grasslands cover $11 \%$; fallow land covers $14 \%$; forests cover $14 \%$; and human settlements cover $10 \%$. Other habitats cover $1 \%$ of the study system. Land use intensity is low and most of the farms in the area are small, at below 10 ha. Many grasslands of varying size and with different management regimes are spread among the arable fields and some abandoned grasslands have been invaded by alien goldenrods (Moroń et al. 2009; Skórka et al. 2010).

\section{Sampling design}

We selected 10 abandoned grasslands; five invaded by goldenrods and five non-invaded. Goldenrods covered over $90 \%$ of the area of invaded grasslands, which is a common situation in invaded habitat patches. Grasslands with goldenrods are usually monospecific stands, with a low number of other plant species
(Moroń et al. 2009). Goldenrods were absent in noninvaded grasslands. All the grasslands studied originated from abandoned wet meadows following the cessation of mowing. All grasslands belonged to Molinietalia association including characteristic plant species like Deschampsia caespitosa, Galium uliginosum, Lychnis flos-cuculi, Molinia caerulea, Sanguisorba officinalis (Supplementary material). The history of the sites was ascertained through extensive interviews with the farmers and landowners. The area of the grasslands was similar for those which had been invaded (mean $\pm \mathrm{SE}=11.2 \pm 0.9$ ha, range 9.2-14.0 ha) and those without goldenrods (mean \pm $\mathrm{SE}=12.0 \pm 1.0$ ha, range 9.0-14.5 ha). The managed grasslands could not be used as a control, because there was no possibility of their being invaded and they were thus of no interest to this study.

All the grasslands were separated from each other by a distance of at least $2 \mathrm{~km}$. They were selected to meet certain criteria: (a) the vicinity of both grassland types were required to have, on average, a similar cover of other grasslands within a $1 \mathrm{~km}$ radius of the grassland patch boundary (invaded grasslands: mean $\pm \mathrm{SE}=$ $13.2 \pm 1.1 \%$, range $10-16 \%$; non-invaded grasslands: $13.4 \pm 1.1 \%$, range $10-17 \%$ ), distance to the river (invaded grasslands: $978 \pm 42 \mathrm{~m}$, range 901-1,123 m; non-invaded grasslands: $1,142 \pm 67 \mathrm{~m}$, range $976-1,321 \mathrm{~m}$ ), forest cover within a $1 \mathrm{~km}$ radius of the grassland boundary (invaded grasslands: $3.8 \pm 1.0 \%$, range $1-7 \%$; non-invaded grasslands: $3 \pm 0.7 \%$, range $1-5 \%$ ) and distance from built-up areas (invaded grasslands: $511 \pm 24 \mathrm{~m}$, range 453-563 m; non-invaded grasslands: $556 \pm 44 \mathrm{~m}$, range 460-674 m); (b) they were required to be located on a similar soil type, namely alluvial soils in river valleys; (c) there should be no pesticide use in their vicinity; (d) the period since the cessation of management should be between eight and 10 years.

Sampling of ants and environmental variables

In July 2006, we randomly selected seven plots of $100 \mathrm{~m}^{2}(10 \times 10 \mathrm{~m})$ in each grassland (in total, 35 plots in invaded grasslands and 35 in non-invaded ones) and searched the ant colonies manually (Maes et al. 2003) by examining all the possible nest sites. One plot was checked for a period of around $2 \mathrm{~h}$ by two observers. To avoid counting of a colony more than once every colony was marked with a small 
numbered pole. For each colony, we collected 5-10 workers and preserved them in $75 \%$ ethanol. Ants were identified initially in field and the identification was later confirmed in the laboratory by inspecting all individual workers under a microscope. The key produced by Czechowski et al. (2002) was used for identification. We also counted all the plant species (Supplementary material) in every $100 \mathrm{~m}^{2}$ plot and measured the distance of each plot from the edge of the grassland because these variables could affect colony density and ant species number. All the surveys were done under favourable weather conditions, with no rain and with temperatures of above $20^{\circ} \mathrm{C}$.

Estimation of colony size

In every colony of Myrmica spp. we estimated the number of workers by the method described in an earlier work (Skórka et al. 2006). It is based on the tendency of workers to climb up wooden sticks placed in their nests and it assumes that the number of workers removed on a series of sticks is related to the total number of workers within the colony. Once a Myrmica spp. colony was found, we opened the top part slightly, holding back the grasses with our hands, until the first chambers containing larvae could be reached. Then we inserted a wooden stick $(3.5 \times 3.5 \times 20 \mathrm{~cm})$ into the colony vertically. After ten seconds, the stick was removed and put into a plastic bag to prevent the ants from escaping and another one was immediately put into the colony. This procedure was repeated six times for every colony. We then used the equations given in Skórka et al. (2006) to estimate the number of workers in the colony.

We applied this method to Lasius sp. and Formica sp. colonies as well, despite the fact that the technique has not yet been validated for these ants (Skórka et al. 2006). We have therefore only provided the raw number of workers climbing up wooden sticks for those species and it should be treated as an index of worker number.

\section{Foraging distance}

The estimation of foraging range was carried out in 2007 in three invaded and three non-invaded grasslands. We estimated the foraging distances for Myrmica scabrinodis and M. rubra, since these were the only two ant species present in both kinds of grassland with a large enough number of colonies to permit us to perform reasonable statistical comparison between the grassland types. The estimation of foraging distances was made on the basis of food items of different colours, which were brought to the colony by ant workers from known distances. We used crumbled cakes (Biszkopty Wawel Corp.), which were placed in narrow strips around the colony in a radius of 100 and $200 \mathrm{~cm}$. Each cake-strip around the colony was a different colour. We used yellow and red dyes applied in food production. The colour of the cake-strips at various distances around the colony was randomized; however, one colour was not used twice at any colony. The observer sat by the colony in a specially constructed frame made from a deckchair and noted the number of workers emerging and reentering. We counted all the workers that brought pieces of the cakes and noted the distance from which the food was collected.

One 6-h observation of foraging behaviour was conducted at each colony. The observation usually started between 8 a.m. and 10 a.m. When the observation was finished, we measured the colony size by using the same method as described above (Skórka et al. 2006). We surveyed three colonies of M. scabrinodis and three colonies of M. rubra in each grassland.

Foraging distances may be affected by the colony density of a competing species or by conspecifics (Kugler 1984; Gordon 1995; Elmes et al. 1998; Weeks et al. 2004). Thus the differences between foraging distance for the ants from the invaded and non-invaded grasslands could be the result of differences in ant colony density. To control this effect, we removed all the ant colonies in 3-m radius around the focal colony in the non-invaded grasslands by digging up the entire colony and moving it to another part of the grassland. The removed ants colonies belonged to Myrmica sp. and Lasius sp. We removed ant colonies in the early morning of the day when the behavioural observations were done during later hours. The observation of ant foraging behaviour was carried out in the same manner as previously described. Nine colonies of both ant species in three non-invaded grasslands (three colonies of each species per one grassland) were surveyed in this manner.

In summary, for each species we sampled 9 colonies in invaded grassland, 9 colonies in noninvaded grasslands and 9 colonies in non-invaded grasslands surveyed in a manner to control for the differences in a colony density. Thus, for each species 27 colonies were sampled in total. 
Statistical analysis

We used a generalized linear mixed model (GLMM) with an identity link function to study the effects of a goldenrod invasion on the number of ant species and ant colony density (number of ant colonies per $100 \mathrm{~m}^{2}$ plot). The explanatory variable was habitat type (invaded grasslands vs. non-invaded ones). We also included the number of plant species recorded within a $100 \mathrm{~m}^{2}$ plot and the distance to the grassland edge as covariates. Grasslands identity was included as a random effect.

A canonical ordination was employed in order to relate the colony density of the individual species to the environmental variables (grassland type, number of plant species and distance to the grassland edge) using the CANOCO 4.5 package (Lepš and Šmilauer 2003). Since the length of the longest gradient in DCCA was so short (1.4), we opted to use Redundancy Analysis (RDA) for this ordination. Variables in the RDA were introduced by a forward stepwise procedure and their statistical significance was tested by 499 permutations.

The GLMM was also used to test the effect of the goldenrod invasion on the size of the ant colonies in $M$. scabrinodis, M. rubra, Lasius niger and L. flavus; only these species were present in the invaded grasslands.

The effect of goldenrod invasion on the distance covered by foraging workers was only estimated for the two most abundant ant species, Myrmica scabrinodis and $M$. rubra, and two types of analysis were performed. First, we used G-tests to compare the distribution of the number of workers that carried crumbled cakes from various distances in the invaded and non-invaded grasslands. All the data were pooled across grasslands of a given type and thus the result of this analysis may be biased owing to data dependence and should be treated with caution. It was performed in order to visualize the general pattern in foraging. To avoid the problem of data dependency we performed a GLMM where we tested if the mean number of ants carrying cake pieces per $6 \mathrm{~h}$ from various distances within the territory differed between the invaded and non-invaded sites (including sites with experimentally controlled colony density). In this analysis, we included the combination of colour strips as an additional factor and the estimated number of workers in the colony as a covariate. Grassland and colony identities were assigned as random factors. SPSS 19 software was used for the calculations.
Table 1 Ant species composition and number of colonies found in non-invaded grasslands and invaded by alien goldenrods

\begin{tabular}{lccr}
\hline Species & Non-invaded & Invaded & Sum \\
\hline Myrmica scabrinodis & 79 & 24 & 103 \\
Myrmica rubra & 43 & 20 & 63 \\
Lasius niger & 18 & 10 & 28 \\
Myrmica ruginodis & 14 & 0 & 14 \\
Lasius flavus & 4 & 4 & 8 \\
Formica fusca & 7 & 0 & 7 \\
Myrmica rugulosa & 3 & 0 & 3 \\
Formica cunicularia & 1 & 0 & 1 \\
Total number of species & 8 & 4 & 8 \\
Total number of colonies & 169 & 58 & 227 \\
\hline
\end{tabular}

\section{Results}

Species richness and abundance

In total, eight ant species, with 169 colonies, were found in grasslands with native vegetation and only four species, with 58 colonies, in grasslands invaded by alien goldenrods (Table 1). None of the species found in invaded grassland were different from those found in the non-invaded grasslands with native vegetation. When the data from the $10 \times 10 \mathrm{~m}$ plots were analysed, the number of ant species and colonies per $100 \mathrm{~m}^{2}$ plot was smaller in the invaded grasslands than in the non-invaded ones (Table 2; Fig. 1). Both the number of ant species and the density of ant colonies were positively dependent on plant species richness, but only in the grasslands invaded by invasive alien goldenrods (Table 2; Fig. 2). Mean ( \pm standard error) number of plant species per $100 \mathrm{~m}^{2}$ plot was $8.1 \pm 1.0$ in invaded grasslands and $12.9 \pm 1.0$ in non-invaded ones. Interactive effects were also found for distance from the grassland edge and grassland type, with a higher number of ant species and colonies near the edge of the grasslands invaded by goldenrods, but not the non-invaded ones (Table 2; Fig. 2).

In summary, the RDA demonstrated that the first two ordination axes explained a $28 \%$ variation in species composition, of which environmental variables explained $98 \%$. First ordination axis differentiated invaded grasslands from non-invaded ones and 
Table 2 Results of the general linear mixed model showing factors affecting the number of ant species and density of ant colonies in the grasslands studied $(n=35$ plots in invaded grasslands and $n=35$ plots in non-invaded grasslands)

\begin{tabular}{|c|c|c|c|c|c|c|}
\hline \multirow[t]{2}{*}{ Effect } & \multicolumn{3}{|c|}{ Ant species richness } & \multicolumn{3}{|c|}{ Density of ant colonies } \\
\hline & df & $\mathrm{F}$ & $P$ & df & $\mathrm{F}$ & $P$ \\
\hline Grassland type & $1,58.4$ & 20.928 & $<0.001$ & $1,63.5$ & 36.972 & $<0.001$ \\
\hline Distance to edge & $1,62.5$ & 10.286 & 0.002 & $1,62.6$ & 0.159 & 0.692 \\
\hline Plant species richness & $1,59.7$ & 20.928 & $<0.001$ & $1,62.1$ & 6.306 & 0.015 \\
\hline Interaction term: grassland type $\times$ distance to edge & $1,60.9$ & 3.080 & 0.084 & $1,63.9$ & 4.881 & 0.031 \\
\hline Interaction term: grassland type $\times$ plant species richness & $1,60.5$ & 13.723 & $<0.001$ & $1,63.9$ & 11.856 & 0.001 \\
\hline
\end{tabular}

"Grassland type" was categorical variable indicating invaded grasslands and non-invaded ones

"Distance to edge" was a distance of the $100 \mathrm{~m}^{2}$ plot from the grassland edge; "Plant species richness" was a number of plant species recorded in a $100 \mathrm{~m}^{2}$ plot

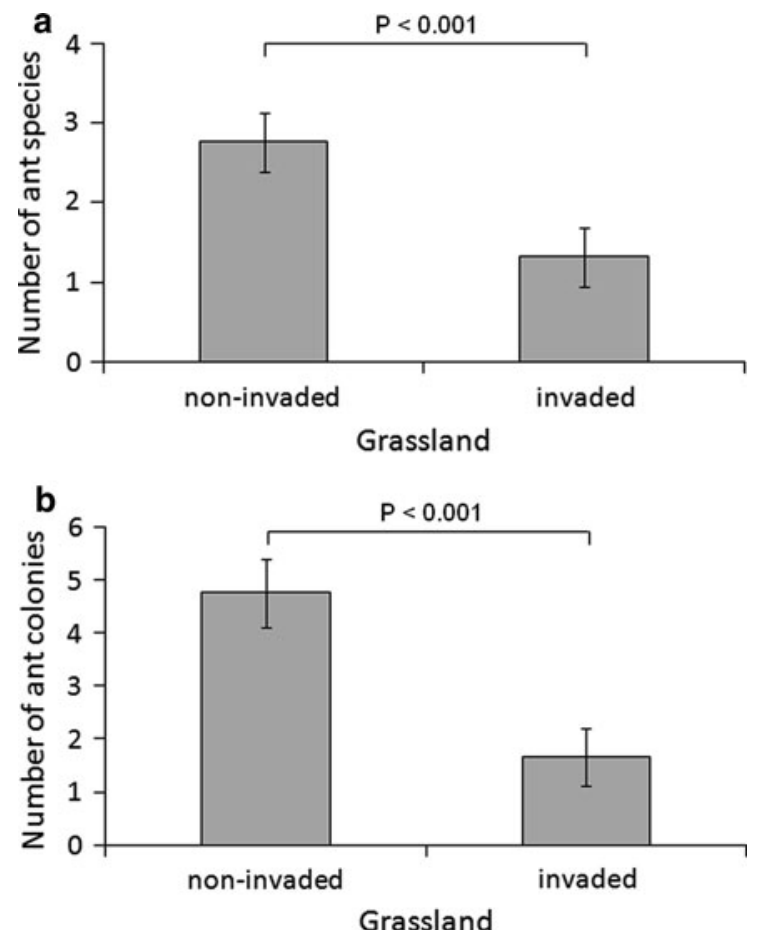

Fig. 1 The effect of goldenrod invasion on a ant species richness and $\mathbf{b}$ number of ant colonies per $100 \mathrm{~m}^{2}$. The means are presented with $95 \%$ confidence intervals

it also represented a gradient of the increasing number of plant species (Fig. 3). The second axis represented an increasing distance from a grassland edge (Fig. 3). The variables which significantly contributed to the explanation of density of ant colonies of different species were grassland type $(\mathrm{F}=19.22, P=0.002$; Fig. 3) and number of plant species $(\mathrm{F}=4.970$, $P=0.002$, Fig. 3).

\section{Colony size}

The number of workers in colonies was significantly lower in the grasslands invaded by alien goldenrods than it was in those with native vegetation in Myrmica scabrionodis $\left(\mathrm{GLMM} \mathrm{F}_{1,68.8}=26.509 ; P<0.001\right.$; Fig. 4) and Myrmica rubra (GLMM $F_{1,56.2}=37.687$, $P<0.001$; Fig. 4). Similar results were found for the index of colony size in Lasius niger (GLMM $F_{1,22.3}$, $\mathrm{F}=20.503 ; P<0.001$; Fig. 4), but not for Lasius flavus $\left(\mathrm{GLMM} \mathrm{F}_{1,1.0}=2.642 ; P=0.354\right.$; Fig. 4$)$; however, the sample size in the latter species was very small (Table 1).

Other species occurred only in non-invaded grasslands (Table 1). The estimated mean ( \pm standard error) number of workers in colonies of Myrmica ruginodis was $1055.4 \pm 138.7 \quad(\mathrm{n}=14$ colonies $)$. Mean numbers of workers removed from the colonies of Myrmica rugulosa, Formica fusca, Formica cunicularia were $51.7 \pm 8.5 \quad(\mathrm{n}=3), \quad 28.2 \pm 12.7$ $(\mathrm{n}=4), 21(\mathrm{n}=1)$, respectively.

Foraging distances

When the data were pooled for all colonies, in both Myrmica scabrinodis $\left(\chi^{2}=93.41, P<0.001\right)$ and $M$. rubra $\left(\chi^{2}=6.691, P=0.010\right)$ more workers travelled longer distances for food in the invaded grasslands than in the non-invaded ones (Fig. 5).

When the means were analysed, more workers in Myrmica scabrinodis carried crumbled cakes from larger distances in the invaded grasslands than in the non-invaded grasslands with native vegetation (interaction term in Table 3; Fig. 5). This pattern was also 
Fig. 2 Effects of the distance from the grassland edge $(\mathbf{a}, \mathbf{b})$ and the number of plant species $(\mathbf{c}, \mathbf{d})$ on the ant species richness and number of ant colonies per $100 \mathrm{~m}^{2}$ plot in the grasslands invaded by goldenrods (black dots and lines) and the non-invaded grasslands (grey dots and lines)
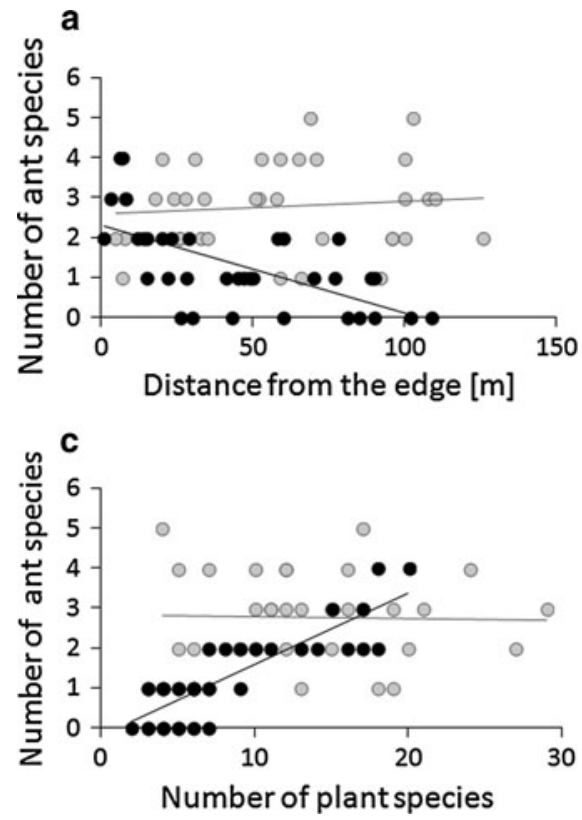
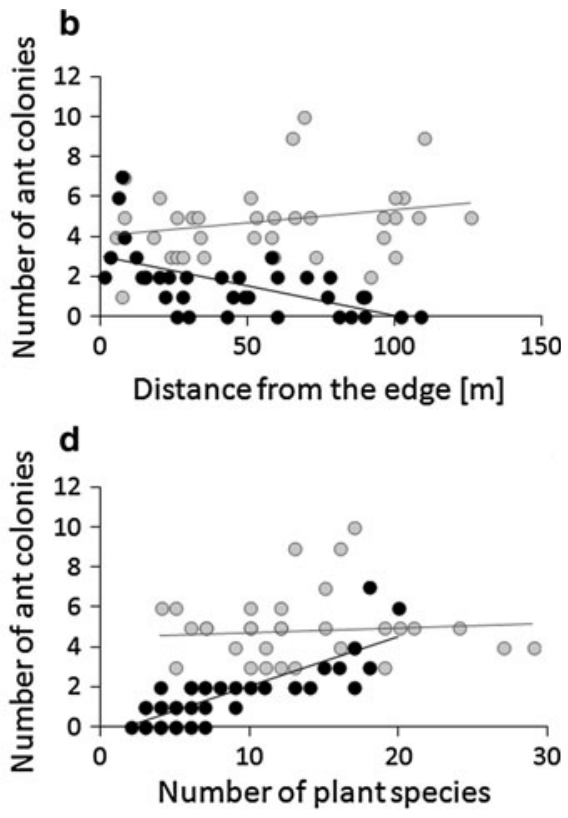

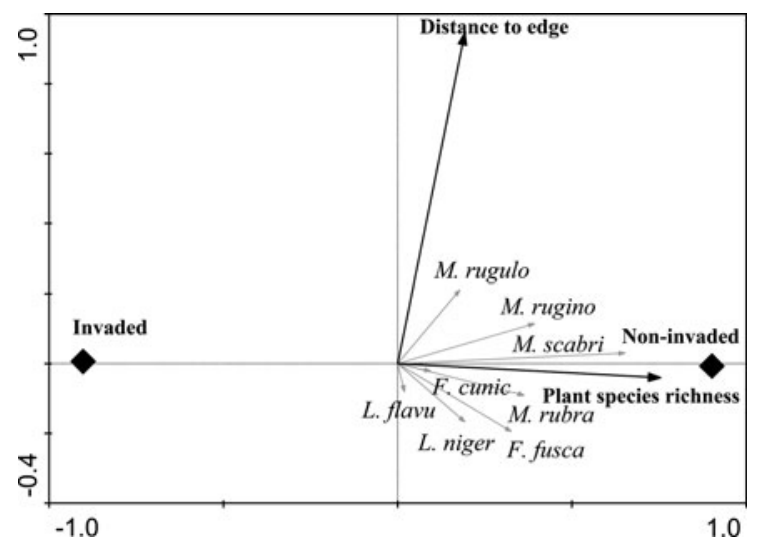

Fig. 3 Effect of continuous (black arrows) and nominal (black diamond) environmental variables on ant species composition in the RDA ordination. The ant labels are the abbreviated scientific names presented in Table 1

noticeable in $M$. rubra; however, statistically, it was marginally non-significant (Table 3; Fig. 5). The removal of the ant colonies in the vicinity of the ant colonies being investigated in the non-invaded grasslands did not increase the workers' foraging distances (Fig. 5). The colour combination of the strips of crumbled cake had no effect on foraging distances of workers (Table 3; Fig. 5). The effect of colony was also non-significant (Table 3; Fig. 5).

\section{Discussion}

Our study revealed that grasslands invaded by goldenrods had a lower number of ant species and colonies. It has also provided new data on colony size and foraging distances, which were, respectively, lower and longer in the invaded habitats than in the noninvaded ones. Comparison to other published results is difficult owing to the still small number of studies on the effects of invasive plants on ant communities and the equivocality of their results. It seems that the invasive plants producing food which is used by ants, such as nutritious seeds, for example, or plants that enhance aphid populations may favour native ant populations (Alba-Lynn and Henk 2010; Lescano and Farji-Brener 2011). However, this is not always the case, as it was demonstrated by French and Major (2001), who showed that the exotic plant Acacia saligna, which produces ant-dispersed seeds, did not affect the species richness of ants and negatively affected their abundance. Other studies (Lindsay and French 2006; Simao et al. 2010) also indicate that habitats with invasive plants reduce ant abundance and species richness and that ants are among the arthropod group most sensitive to plant invasion. Our results agree with the later studies and indicate that invasions act in similar way to local habitat disturbances 
Fig. 4 Mean number of workers in the colonies of a Myrmica scabrinodis, b $M$. rubra and the mean number of workers removed on wooden sticks from the colonies of c Lasius niger and $\mathbf{d}$ Lasius flavus on the non-invaded grasslands and those invaded by goldenrods. The means are presented with $95 \%$ confidence intervals
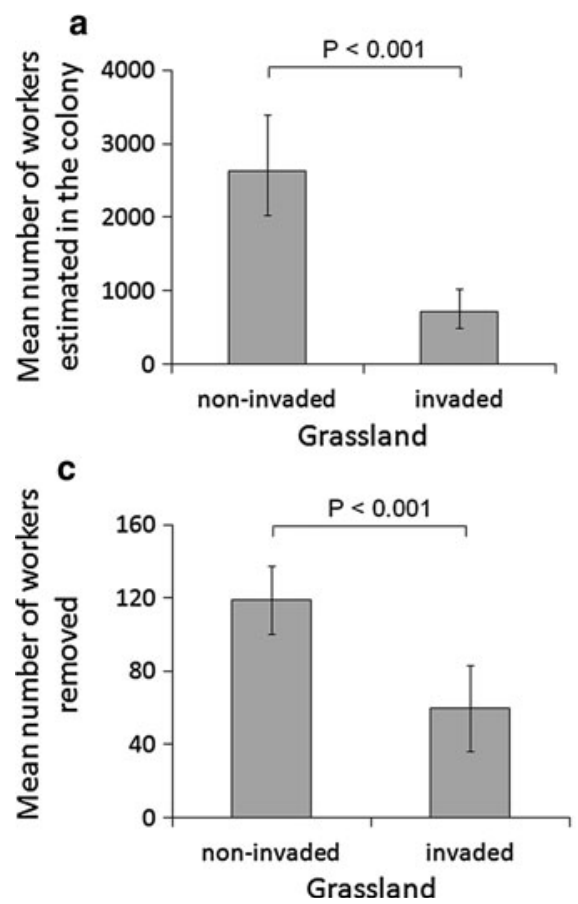
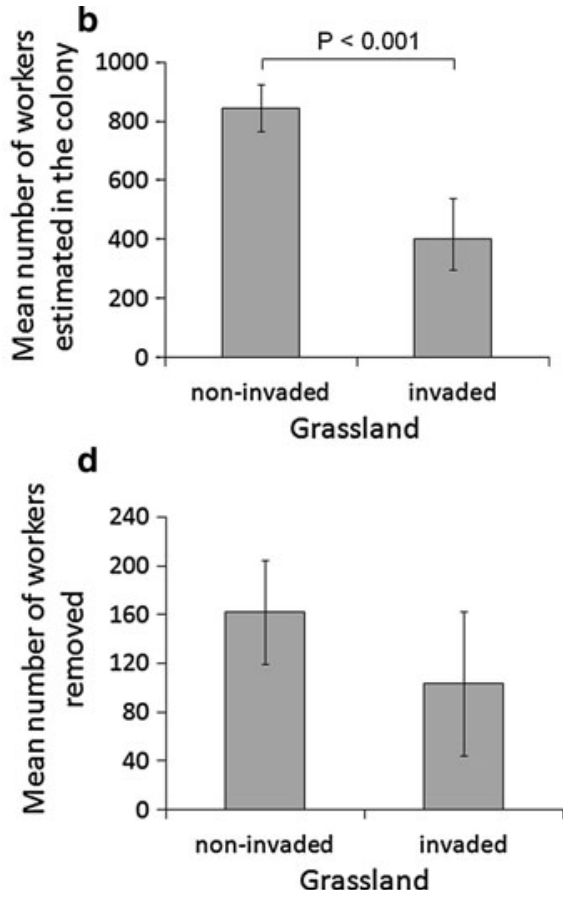

Table 3 Results of the general linear mixed model showing factors affecting the number of $M$. scabrinodis and $M$. rubra ant workers carrying crumbled cakes to their nests

\begin{tabular}{|c|c|c|c|c|c|c|}
\hline \multirow[b]{2}{*}{ Effect } & \multicolumn{3}{|c|}{ Myrmica scabrinodis } & \multicolumn{3}{|c|}{ Myrmica rubra } \\
\hline & df & $\mathrm{F}$ & $P$ & df & $\mathrm{F}$ & $P$ \\
\hline Grassland type & $2,39.6$ & 2.499 & 0.095 & $2,39.7$ & 0.950 & 0.395 \\
\hline Distance & $1,39.5$ & 62.761 & $<0.001$ & $1,39.4$ & 17.077 & $<0.001$ \\
\hline Colony size & $1,13.5$ & 0.160 & 0.696 & $1,27.9$ & 0.011 & 0.917 \\
\hline Colour combination & $1,4.4$ & 0.151 & 0.716 & $1,5.1$ & 2.171 & 0.200 \\
\hline Interaction term: distance $\times$ grassland type & $2,39.5$ & 62.761 & $<0.001$ & $2,39.3$ & 3.015 & 0.061 \\
\hline
\end{tabular}

"Distance" was a categorical variable indicating the distance (1 and $2 \mathrm{~m}$ ) from the colony at which the crumbled cakes were set. "Colour combination" indicates the two possible colour combinations of the crumbled cakes around ants' colonies. For other explanations: see Table 2

(Linksvayer and Janssen 2009), which have a profound effect on number of ant species and colonies.

The negative effect on ant diversity and the number of colonies indicates that only some species are able to live in invaded grasslands with goldenrods growing in dense monospecific stands. The goldenrods lead to a nested pattern of ant communities, because no new species occur in the invaded grasslands. The negative effect of goldenrods on the number of species may be both direct and indirect. Goldenrods out-compete native plants and change the habitat structure, soil properties and microclimatic characteristics (VoserHuber 1992; Weber 2001; de Groot et al. 2007; Pisula and Meiners 2010). Interestingly, the most abundant species in the grasslands with goldenrods were M. scabrinodis, M. rubra and Lasius niger. These 

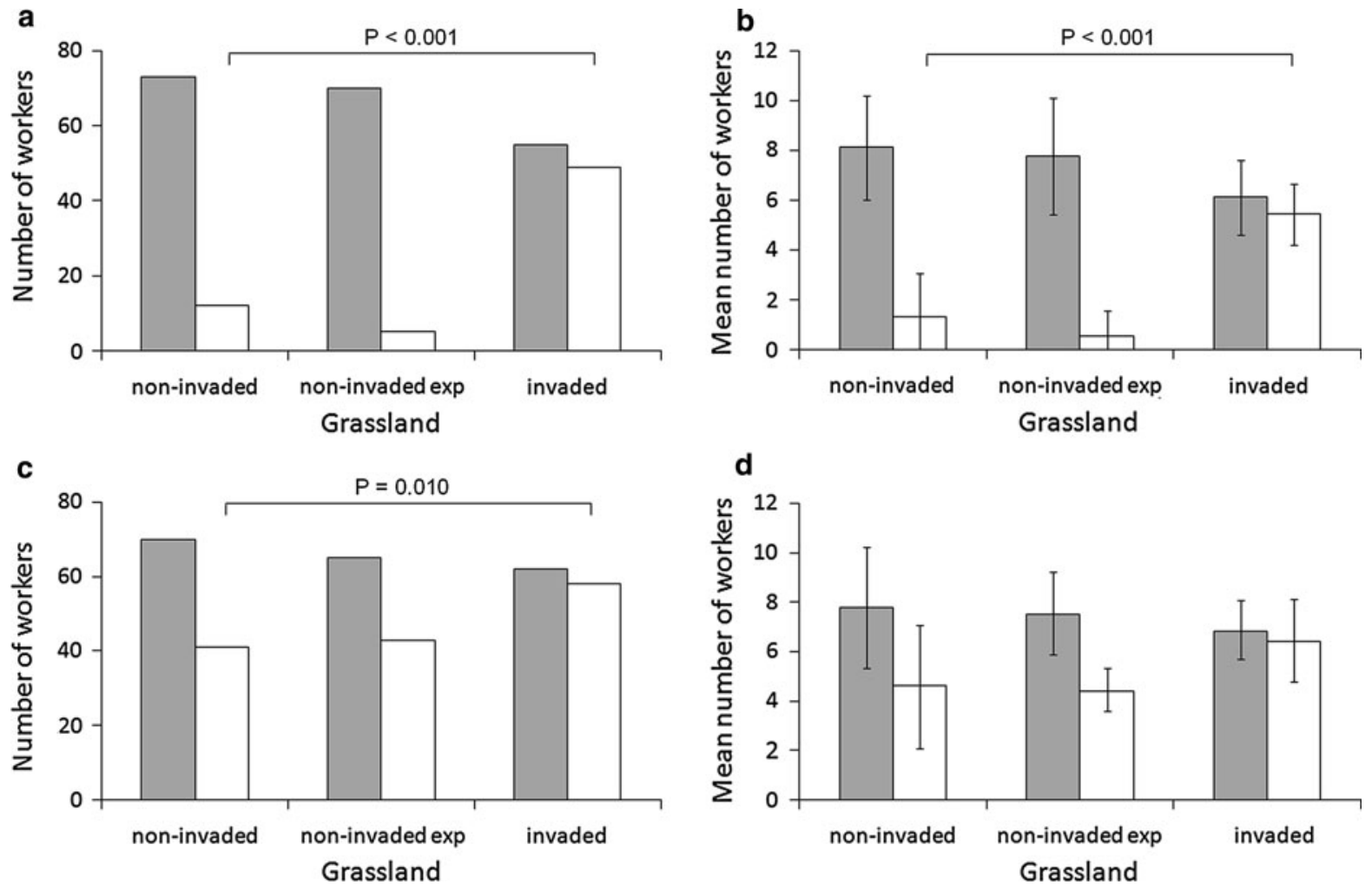

Fig. 5 The total and mean number of workers, per 6 h, carrying crumbled cakes from a distance of $1 \mathrm{~m}$ (grey bars) and $2 \mathrm{~m}$ (white bars) to the colonies of the Myrmica scabrinodis (a, b) and $M$. rubra $(\mathbf{c}, \mathbf{d})$ located in non-invaded grasslands (non-

species are known for their high tolerance to various environmental conditions (Elmes et al. 1998; Dauber and Wolters 2005). On the other hand, other species, such as $M$. ruginodis, are only able to occur in a narrow, species-specific temperature, moisture and insolation range (Elmes et al. 1998).

We also cannot exclude the possibility that goldenrods act on ant communities indirectly via the trophic cascade (Sanders and Platner 2007). They negatively affect almost all groups of organisms (de Groot et al. 2007; Moroń et al. 2009; Skórka et al. 2010) and may reduce the potential food for ants (Sanders and Platner 2007). One possible indicator may be the absence of ants of the Formica genus in meadows with goldenrods, whereas in non-invaded grasslands colonies of $F$. fusca and $F$. cunicularia were found. Both of these species are mainly predaceous and scavenging (Czechowski et al. 2002) and thus the reduction of other arthropod groups (Moron et al. 2009) could be the main reason for their absence.

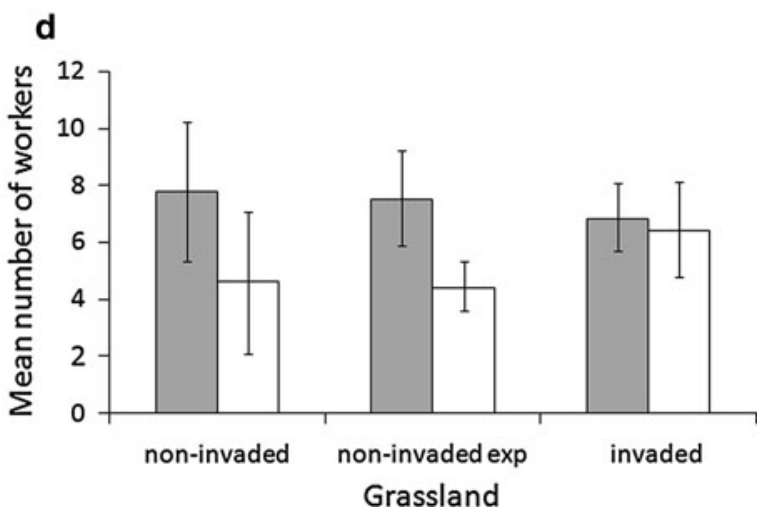

invaded), native vegetation with an experimentally reduced density of other ant species (non-invaded exp) and the grasslands invaded by goldenrods (invaded). The means are presented with $95 \%$ confidence intervals

Invaded and non-invaded grasslands differed structurally. Thus, one may expect that our estimations of number of ant species and their colonies may be biased by different detection probability of ant colonies in two grassland types. Goldenrods often grow in high density but because there are few other plant species this creates many places of bare ground in invaded grasslands. This was a reason why the searching of ant colonies in the goldenrods was actually easier than in non-invaded grasslands. In the latter, the grass is dense which makes searching sometimes difficult. However, this means that our results are conservative. Moreover, we searched ground very carefully and we believe that we found close to $100 \%$ of all colony present in plots. Other method of estimation ant species richness which is baiting produces results that are highly dependent on colony density and behaviour of workers (SchlickSteiner et al. 2006) which, as we demonstrated, differed between invaded and non-invaded grasslands. The colony size of most species was lower in the 
grasslands with goldenrods and, in comparison to the non-invaded grasslands, there was a lack of ant species which tend to have colonies containing a high number of workers, such as M. rugulosa (Radchenko and Elmes 2010). Our results provide the first estimates of the effects of invasive plants on colony size, which is usually very difficult to measure and is omitted in most of the studies to date. A colony's size is regarded as an important indication of its competitive ability and food supply (Sorvari and Hakkarainen 2007; Planque et al. 2010); thus the invasion of goldenrods may negatively affect ants fitness components. Lower colony size may result from unfavourable site-specific conditions and may also be an indication that the colony is subsiding. Colony size mediates various aspects of ants' live, and, in particular, their reproductive strategies (Planque et al. 2010). Thus, if goldenrods affect ant colony size and colony density, it is probable that ants in invaded patches differ in their reproductive modes from those in non-invaded areas. This is one of the questions demanding an answer in future studies.

We found interesting spatial patterns in the distribution of ant colonies in the invaded grasslands with an apparent edge effect there. More ant colonies were near edges of the invaded grasslands, but not in the non-invaded ones, where the number of ant colonies was similar near edge and centre of the habitat patch. However, this was different from the edge effect which is understood as an elevated number of species or individuals at patch edges (Ivanov and Keiper 2010). The number of species and colonies at the edges in the invaded grasslands was either lower or similar to the number found in the non-invaded grasslands. Thus the edge effect in our study probably results from colony extinctions in central parts of the invaded grasslands, rather than from favourable conditions at the edges, because no edge effect was observed in the non-invaded grasslands. Nevertheless, the higher number of colonies at the edges of the invaded grasslands suggests that this part of the invaded habitat is somehow more suitable for ants. We also cannot exclude the possibility that the higher number of ants at the edges of the invaded grasslands results from colonization events. However, our study grasslands were mostly surrounded by arable fields, which may be a barrier as regards colonization by insects (Öckinger et al. 2012); this explanation should therefore be tested in detail in a further study. The edge effect was also not attributable to plant species richness, as we found no relationships between the distance to the edge and the number of plant species.

The effect of plant species number on the number of ant species in the invaded sites is interesting and the links between the two may be both direct and indirect. First, some plant seeds are a food resource for ants (Wolff and Debussche 1999; Gove et al. 2007). Moreover, ants use plant structures in order to settle and built nests. For example, Myrmica ants often build colony in grass tufts (Elmes et al. 1998; Skórka et al. 2006), of which there are a shortage in grasslands invaded by goldenrods. Also, aphids parasitizing on native plants provide a food supply for ants, but we did not observe any aphid colonies on goldenrods in the studied grasslands, though, there were few aphid colonies on native plants in the invaded grasslands. In the non-invaded grasslands neither the plant species number nor the edge proximity affected the ant communities, indicating that plants are not a limiting factor and habitat suitability is probably equal across the entire area of the non-invaded grasslands. Plant species are numerous in the non-invaded grasslands which are known for their high level of biodiversity (Skórka et al. 2007; Moroń et al. 2008a, b; Krause et al. 2012).

Our results have revealed for the first time that the invasion of alien plants affects the foraging behaviour of native ants. In the invaded grasslands, the ants often foraged at longer distances from the colonies than they did in the non-invaded habitat. The difference between the invaded grasslands and the non-invaded ones remained significant even after the experimental reduction of the ant colony density in the latter. This suggests that the foraging range of ants was not affected by inter-colony competitive interactions in the non-invaded grasslands of our study area. Thus the longer distances covered by the ant workers in the invaded habitat may indicate that (a) the ants have increased their foraging efforts in order to find food and (b) the food itself is probably in shortage there, as discussed previously. The higher foraging effort may indicate that colonies should differ in their investments in castes in order to survive in invaded grasslands. Two scenarios are possible, both requiring thorough study. First, colonies may invest more into workers which work far from the colony. This is risky task (Woyciechowski and Kozłowski 1998; Moroń et al. 2008a, b, 2012) and many workers do not return to the colony, which may be also another explanation 
for the smaller colony sizes in the invaded grasslands. Second, as the environmental conditions deteriorate in course of an invasion, the ants may move their colony to another area, or invest more in sexual reproduction and try to colonize other, non-invaded areas. This could also be an auxiliary explanation for the lower colony size and lower density of ant colonies. In our opinion, this work opens new perspectives for further studies on the effect of invasive alien plants on the reproductive and foraging strategies of ants.

Measures to control invasions of alien goldenrods should be undertaken on invaded grasslands. Removing goldenrods from previously invaded areas may be very difficult because of species tolerance and a large seed bank (Voser-Huber 1992; Weber 2001). This could be achieved by mechanical control, e.g., regular mowing for several years and it may require substantial economic input. However, there is a lack of studies on how different management schemes affect ant communities in invaded and non invaded grasslands. Thus, it would be also very interesting to study the effect of various mowing regimes, grazing or burning on the effectiveness of goldenrod removal and how these measures influence ant communities.

Acknowledgments We thank two anonymous referees for critical comments on the manuscript. This study was partially financed by the National Science Centre in Poland under grant number UMO-2011/01/N/NZ8/03211. We would like to thank Janusz Skórka for his help during the collection of the data.

Open Access This article is distributed under the terms of the Creative Commons Attribution License which permits any use, distribution, and reproduction in any medium, provided the original author(s) and the source are credited.

\section{References}

Agosti D, Maryati M, Chung AYC (1994) Has the diversity of tropical fauna been underestimated? An indication from leaf litter studies in a West Malaysian lowland rain forest. Trop Biodiv 2:270-275

Agosti D, Majer JD, Alonso LE, Schultz TR (2000) Ants. Standard methods for measuring and monitoring biodiversity. Smithsonian Institution Press, Washington

Alba-Lynn C, Henk S (2010) Potential for ants and vertebrate predators to shape seed-dispersal dynamics of the invasive thistles Cirsium arvense and Carduus nutans in their introduced range (North America). Plant Ecol 210:291-301
Andersen AN, Majer JD (2004) Ants show the way Down Under: invertebrates as bioindicators in land management. Front Ecol Environ 2:291-298

Andersen AN, Hoffmann BJ, Müller WJ, Griffiths AD (2002) Using ants as bioindicators in land management: simplifying assessment of ant community responses. J Appl Ecol 39:8-17

Clavero M, García-Berthou E (2005) Invasive species are a leading cause of animal extinctions. Trends Ecol Evol 20:110

Clout MN, Williams PR (2009) Invasive species management: A handbook of principles and techniques. Oxford University Press, Oxford

Czechowski W, Radczenko A, Czechowska W (2002) The ants (Hymenoptera, Formicidae) of Poland. MIIZ PAN, Warszawa

Dauber J, Wolters V (2004) Edge effects on ant community structure and species richness in an agricultural landscape. Biodivers Conserv 13:901-915

Dauber J, Wolters V (2005) Colonization of temperate grasslands by ants. Basic Appl Ecol 6:83-91

de Groot M, Kleijn D, Jogan N (2007) Species groups occupying different tropic levels respond differently to the invasion of semi-natural vegetation by Solidago canadensis. Biol Conserv 136:612-617

Dong M, Lu JZ, Zhang WJ, Chen JK, Li B (2006) Canada goldenrod (Solidago canadensis): an invasive alien weed rapidly spreading in China. Acta Phytotaxon Sin 44:72-85

Elmes GW, Thomas JA, Wardlaw JC, Hochberg ME, Clarke RT, Simcox DJ (1998) The ecology of Myrmica ants in relation to the conservation of Maculinea butterflies. J Insect Conserv 2:67-78

Euskirchen ES, Chen J, Bi R (2001) Effects of edges on plant communities in a managed landscape in northern Wisconsin. For Ecol Manag 148:93-108

Fittkau EJ, Klinge H (1973) On biomass and trophic structure of the Central Amazonian rain forest ecosystem. Biotropica 5:4-14

French K, Major RE (2001) Effect of an exotic Acacia (Fabaceae) on ant assemblages in South African fynbos. Aust Ecol 26:303-310

Funk JL, Vitousek PM (2007) Resource-use efficiency and plant invasion in low-resource systems. Nature 446:1079-1081

Gehlhausen SM, Schwartz MW, Augspurger CK (2000) Vegetation and microclimatic edge effects in two mixedmesophytic forest fragments. Plant Ecol 147:21-35

Gordon DM (1995) The development of an ant colony's foraging range. Anim Behav 49:649-659

Gove AD, Majer JD, Dunn RR (2007) A keystone ant species promotes seed dispersal in a "diffuse" mutualism. Oecologia 153:687-697

Herbers JM, Choiniere E (1996) Foraging behaviour and colony structure in ants. Anim Behav 51:141-153

Ivanov K, Keiper J (2010) Ant (Hymenoptera: Formicidae) diversity and community composition along sharp urban forest edges. Biodivers Conserv 19:3917-3933

Krause B, Culmsee H, Wesche K, Bergmeier E, Leuschner C (2012) Habitat loss of floodplain meadows since the 1950s. Biodivers Conserv 20:2347-2364

Kugler C (1984) Ecology of the ant Pogonomyrmex mayri: foraging and competition. Biotropica 16:227-234 
Lach L (2007) A mutualism with a native membracid facilitates pollinator displacement by Argentine ants. Ecology 88:1994-2004

Lenda M, Skórka P, Moroń D (2010) Invasive alien plant species-a threat or an opportunity for pollinating insects in agricultural landscapes? In: Lee TH (ed) Agricultural economics: new research. Nova Science Publishers, New York, pp 67-88

Lepš J, Šmilauer P (2003) Multivariate analysis of ecological data using CANOCO. Cambridge University Press, Cambridge, UK

Lescano MN, Farji-Brener AG (2011) Exotic thistles increase native ant abundance through the maintenance of enhanced aphid populations. Ecol Res 26:827-834

Lindenmayer DB, Fischer J (2006) Habitat fragmentation and landscape change. Island Press, Washington, DC

Lindsay EA, French K (2006) The impact of the weed Chrysanthemoides monilifera ssp. rotundata on coastal leaf litter invertebrates. Biol Invasions 8:177-192

Linksvayer TA, Janssen MA (2009) Traits underlying the capacity of ant colonies to adapt to disturbance and stress regimes. Systems Res Behav Sci 329:315-329

Maes D, Van Dyck H, Vanreusel W, Cortens J (2003) Ant communities (Hymenoptera: Formicidae) of Flemish (north Belgium) wet heathlands, a declining habitat in Europe. Eur J Entomol 100:545-555

Moroń D, Witek M, Woyciechowski M (2008a) Division of labour among workers with different life expectancy in the ant Myrmica scabrinodis. Anim Behav 75:345-350

Moroń D, Szentgyorgyi H, Wantuch M, Celary W, Westphal C, Settele J, Woyciechowski M (2008b) Diversity of wild bees in wet meadows: implications for conservation. Wetlands 28:975-983

Moroń D, Lenda M, Skórka P, Szentgyorgyi H, Settele J, Woyciechowski M (2009) Wild pollinator communities are negatively affected by invasion of alien goldenrods in grassland landscape. Biol Conserv 142:1322-1332

Moroń D, Lenda M, Skórka P, Woyciechowski M (2012) Shortlived ants take greater risks during food collection. Am Nat 160:744-750

Öckinger E, Lindborg R, Sjodin NE, Bommarco R (2012) Landscape matrix modifies richness of plants and insects in grassland fragments. Ecography 35:256-267

Palmer TM (2004) Wars of attrition: colony size determines competitive outcomes in a guild of African acacia ants. Anim Behav 68:993-1004

Pejchar L, Mooney HA (2009) Invasive species, ecosystem services and human well-being. Trends Ecol Evol 24:497-504

Petal J (1982) Intraspecific competition as a way of adaptation to food resources in an ant population (Myrmica limanica jacobsoni). Ekologia Polska 29:421-430

Pisula NI, Meiners SJ (2010) Allelopathic effect of goldenrod species on turnover in successional communities. Am Midl Nat 163:161-172

Planque R, van den Berg JB, Franks NR (2010) Recruitment strategies and colony size in ants. PLoS ONE 5(8):e11664
Radchenko AG, Elmes GW (2010) Myrmica Ants (Hymenoptera: Formicidae) of the old World. In: Iwan D, Czechowski W (eds) Natura optima dux Foundation, Warszawa

Ribas CR, Schoereder JH (2007) Ant communities environmental characteristics and their implications for conservation in the Brazilian Pantanal. Biodivers Conserv 16:1511-1520

Rico-Gray V, Garcia-Franco JG, Palacios-Rios M, DiazCastelazo C, Parra-Tabla V, Navarro JA (1998) Geographical and seasonal variation in the richness of antplant interactions in Mexico. Biotropica 30:190-200

Sanders D, Platner C (2007) Intraguild interactions between spiders and ants and top-down control in a grassland food web. Oecologia 150:611-624

Schlick-Steiner BC, Steiner FM, Moder K, Bruckner A, Fiedler K, Christian E (2006) Assessing ant assemblages: pitfall trapping versus nest counting (Hymenoptera, Formicidae). Insectes Soc 53:274-281

Schlick-Steiner BC, Steiner FM, Pautasso M (2008) Ants and people: a test of two mechanisms potentially responsible for the large-scale human population-biodiversity correlation for Formicidae in Europe. J Biogeogr 35:2195-2206

Simao MCM, Flory SM, Rudgers JA (2010) Experimental plant invasion reduces arthropod abundance and richness across multiple trophic levels. Oikos 119:1553-1562

Skórka P, Witek M, Woyciechowski M (2006) A simple and nondestructive method for estimation of worker population size in Myrmica ant nests. Insect Soc 53:97-100

Skórka P, Lenda M, Tryjanowski P (2010) Invasive alien goldenrods negatively affect grassland bird communities in Eastern Europe. Biol Conserv 143:856-861

Sorvari J, Hakkarainen H (2007) The role of food and colony size in sexual offspring production in a social insect: an experiment. Ecol Entomol 32:11-14

Traveset A, Richardson DM (2006) Biological invasions as disruptors of plant reproductive mutualisms. Trends Ecol Evol 21:208-216

Voser-Huber ML (1992) Goldruten: probleme in naturschutzgebiten. Bundesamt fur Umwelt, Wald und Landschaft (BUWAL), Bern

Walin L, Seppä P, Sundström L (2001) Reproductive allocation within a polygyne, polydomous colony of the ant Myrmica rubra. Ecol Entomol 26:537-546

Weber E (2001) Current and potential ranges of three exotic goldenrods (Solidago) in Europe. Conserv Biol 15:122-128

Weeks RD, Wilson LT, Vinson SB (2004) Resource partitioning among colonies of polygyne red imported fire ants (Hymenoptera: Formicidae). Environ Entomol 33:1602-1608

Wolff A, Debussche M (1999) Ants as seed dispersers in a Mediterranean old-field succession. Oikos 84:443-452

Woyciechowski M, Kozłowski J (1998) Division of labour by division of risk according to worker life expectancy in the honey bee (Apis mellifera). Apidologie 29:143-157

Zanden MJV, Casselman JM (1999) Stable isotope evidence for the food web consequences of species invasions in lakes. Nature 40:1997-2000 